\title{
PROJETO DE VALORIZAÇÃO DA CULTURA AFRODESCENDENTE NOS PROJETOS PEDAGÓGICOS DAS ESCOLAS DE ENSINO MÉDIO DE CURSOS PROFISSIONALIZANTES
}

\author{
Rosana de Ávila Melo Silveira \\ Instituto Federal do Triângulo Mineiro - IFTM - Uberlândia. \\ E-mail: rosanasilveira@iftm.edu.br
}

\begin{abstract}
RESUMO
Este ensaio artigo propõe a analisar uma das principais fontes responsável pela manutenção do mito da democracia racial no Brasil, considerando a contínua discriminação racial que parte da sociedade brasileira vivencia: a Escola Básica. Todos nós sabemos que um dos maiores intento da Educação atual é a formação plena do cidadão. Mas, contraditoriamente, contrastando com esse objetivo, se observa, inclusive por estatística, a contínua exclusão da comunidade negra e parda do processo de formação formal, uma vez que uma parcela significativa desse grupo, não foi inclusa, de forma justa nesse processo. Existe um racismo velado e enraizado em nossa sociedade. Essa discriminação tem afetado por séculos as condições de vida do povo negro em nosso país e tem se perpetuado, pois, há um 'consenso' (idealizado e concretizado) de que existe uma democracia racial no Brasil. Um Racismo Estrutural e Institucional. Segundo o IPEA, mais da metade da população brasileira, é negra e mestiça, possuem baixa renda per capita e baixo índice de escolaridade. Poucas pessoas desse grupo conseguem ingressar em universidades e fazer parte das classes média e alta em nosso país.
\end{abstract}

Palavras-chave: Racismo. Democracia racial. Currículo.

\section{INTRODUÇÃO}

A questão das relações étnico-raciais é um dos principais problemas da nossa sociedade atual; uma vez que a desigualdade racial existente é fruto de discriminação dissimulada, que trata um grupo de forma aparentemente igual em relação a outro, mas não é! O pouco acesso e as poucas condições de permanência, dos negros e mestiços nas instituições de ensino, tem demonstrado falhas históricas, preconceitos e racismo em toda a nossa sociedade.

A falta de conhecimento, discussão e reconhecimento dessa questão nas escolas, são também agravantes, pois, além de expor a falácia no projeto de ensino inclusivo e para todos, ela remete a ideia de quem perpetua o racismo estrutural em nossa sociedade. Dessa forma, destacamos a responsabilidade das instituições de ensino, com seus Projetos Pedagógicos, e seu corpo docente, nessa questão. Os negros, brancos e indígenas não chegam ao mundo conscientes das circunstâncias que transformaram as diferenças fenotípicas em desigualdades de oportunidades sociais (SILVÉRIO, 2007).

O Objetivo Geral é os Projetos Políticos Pedagógicos (PPP) do médio de cursos profissionalizantes, perante as leis federais 10639/2003 e 11645/2008. Este trabalho 
tem, assim, o propósito de expor os Projetos Políticos Pedagógicos (PPP) do Ensino Básico do Brasil, perante as leis federais 10639/2003 e 11645/2008.

Considerando que o PPP é um documento no qual estão registradas as ações e projetos da comunidade escolar, e que o mesmo é fruto da interação entre os objetivos e as prioridades fixadas pela coletividade; é justamente nesse documento que esperamos identificar os entraves que tem impedido a construção de uma sociedade mais justa e menos preconceituosa.

\section{DESENVOLVIMENTO}

A Metodologia utilizada será a pesquisa bibliográfica na qual serão avaliadas as propostas pedagógicas com base nas referências conceituais do trabalho. Trata-se de um procedimento teórico, com leitura e fichamento do material coletado e posteriormente análise de conteúdo.

Segundo Fonseca (2002) a pesquisa bibliográfica é feita a partir do levantamento de referências teóricas já analisadas, e publicadas por meios escritos e eletrônicos, como livros, artigos científicos, páginas de web sites. De acordo com Gil (2007) um dos principais exemplos de Pesquisas Bibliográficas são as investigações sobre ideologias ou aquelas que se propõem à análise das diversas posições acerca de um problema, o que reflete o caso desta pesquisa aqui apresentada que buscará verificar o interesse dos projetos em valorizar a cultura afrobrasileira e africana.

O Racismo está na escola e prejudica milhões de pessoas no Brasil, todos os dias. Muitas destas escolas, não fazem nada a respeito, e continuam omissas frente à tanta dor e sofrimento de crianças e jovens. Iasmin Soares (2019), no texto "Minha experiência como vítima de racismo na escola" conta parte desta realidade:

$\mathrm{Na}$ minha vida escolar sofri com muitas situações de racismo. No ensino fundamental II foi onde eu comecei a querer me embranquecer para conseguir me enturmar e para descolar algum "crush", mas nada que eu alterasse no meu visual mudava a minha condição de ser negra. Logo no sexto ano, eu só ia para a escola de rabo de cavalo, bem apertado para meu cabelo não "afuasar". Nesse período reclamavam que meu cabelo não deixava enxergar o quadro(lousa), então fui sentar nas carteiras de trás da sala de aula. No sétimo ano, um menino da minha sala que sentava na minha frente chegou em mim e durante nossa conversa ele falou que eu deveria alisar meu cabelo porque ficaria mais bonito. Pensei muito nisso o dia inteiro e dei um jeito de alisar meu cabelo. No outro dia cheguei com o cabelo alisado por chapinha, mas não adiantou muito porque eu tenho o cabelo bastante volumoso e só esse método não seria suficiente para tornar meu cabelo estirado aos moldes europeus, os colegas de sala perceberam e riam muito perguntando o que eu tinha feito para o meu cabelo ficar pior ainda. (SOARES, 2019, s/p) 
Assim como Iasmim, muitas crianças e jovens se veem sozinhos frente à humilhações, o que evidencia a falta de preparo de professores e direção da escola para intervir e modificar tais situações.

\begin{abstract}
A escola, como lócus da construção do conhecimento e cidadania, não pode continuar ignorando o que vem acontecendo dentro do seu espaço. Sabe-se que estamos numa sociedade cujo discurso dominante coloca nas mãos dos indivíduos a responsabilidade do próprio destino, aconselhando a todos de que somente a educação é o instrumento de emancipação social e econômica, mas ignora todo o racismo secular. Ainda assim, essa mesma sociedade tem negligenciado uma escola acolhedora para que as crianças negras possam desenvolver suas potencialidades na construção de saberes. Portanto é imperioso mudarmos o discurso, mudarmos a escola. (CORRÊA, 2018, p. 18)
\end{abstract}

Sabemos que docentes e estudantes racistas existem, prova disso são as inúmeras denúncias, felizmente hoje cada mais comuns, realizadas todos os dias. Muito ainda precisa ser feito para modificar padrões racistas nas escolas, a começar na sala de aula com punições rígidas e rápidas a comportamentos ofensivos de todo tipo. Cabe ao/à professor/a ser o/a primeiro/a não aceitar este tipo de situação em suas aulas, mas se no caso for ele/a o/a racista, cabe à escola garantir a denúncia e a segurança para quem está sendo desrespeitado/a.

Um dos caminhos para a superação do Racismo na Escola é a formação continuada, como ocorreu no projeto "Semana Integrada de Combate ao Racismo" na cidade de Salvaterra- Ilha de Marajó - Pará, em 2015, realizada na Escola Professor Ademar Nunes de Vasconcelos, entre outros professores.

As aprendizagens que os (as) estudantes adquiriram no período de realização do projeto se tornaram visíveis no processo de valorização da cultura africana e afro-brasileira, na elevação da autoestima3, que teve por consequência a queda na evasão escolar4 e o aumento do interesse pela escola. $\mathrm{O}$ projeto foi planejado e executado de forma a valorizar a interdisciplinaridade e teve por objetivo despertar e sensibilizar o corpo docente, discente e a comunidade para os malefícios do racismo estrutural de nossa sociedade. Para isso, foram realizadas palestras, debates, exibições de vídeos documentários, apresentações teatrais e musicais, sempre como instrumentos pedagógicos para tratar da temática história da África e cultura afro-brasileira. A culminância do projeto se deu com ampla participação da comunidade local e dos municípios vizinhos, com a escolha da beleza negra nas modalidades feminina e masculina e com uma caminhada pelo centro urbano da cidade para exercitar o direito de expressão e manifestação política da comunidade escolar, iniciativa que chamou a atenção da sociedade para a problemática do combate ao racismo. Na caminhada, os (as) estudantes exibiram o material que produziram para que toda comunidade visse. A unidade escolar Prof. Ademar Nunes de Vasconcelos recebe alunos de 16 comunidades remanescentes de quilombos, e a ação dos (as) docentes é fundamental na luta contra o racismo e a superação de estereótipos ligados_à população negra e quilombola. (ANDRADE, 2015, s/p) 
Uma escola Antirracista é necessária, cabe a cada profissional que lá trabalha construir este novo modo de viver a escola, aos/às estudantes e suas famílias cabe cobrar por estas importantes mudanças.

\section{CONSIDERAÇÕES FINAIS}

Vivemos numa sociedade marcada por episódios contínuos de opressão e coerção. Infelizmente, as políticas públicas de promoção à diversidade racial, não tem diminuído eficazmente as taxas de desigualdades entre negros e brancos. Nem tolhido o racismo presente nos diferentes segmentos da sociedade. E o porquê disso?

A resposta provável para essa problemática se encontra provavelmente nos próprios espaços escolares, que em sua maioria tem mantido o status quo (expressão do latim que significa "estado atual”). O status quo está relacionado ao estado dos fatos, das situações e das coisas, independente do momento.

Precisamos estar dispostos a romper e denunciar essa situação instituída no interior das escolas, e estas precisam ser estudadas, refletidas e mudadas. Muitas delas, mesmo sendo opressoras, não são intencionais, todavia é preciso revê-las, pois não podemos mais aceitar o Racismo sutil e ao mesmo tempo violento que ocorre em nossas experiências educativas.

\section{REFERÊNCIAS}

ANJOS; R. S. A. dos. A África, a Educação Brasileira e a Geografia. In: Sales; Augusto dos Santos (Org.) Educação anti-racista: caminhos abertos pela Lei Federal $\mathrm{n}^{\mathbf{o}}$ 10.639/03. Brasília, 2005.p. 167-184.

ANDRADE, Vinícius Darlan Silva. Um caminho estratégico contra evasão escolar e fortalecimento da autoestima. CEERT. Disponível em: https://ceert.org.br/dialogandopraticas/pratica/vinicius?gclid=CjwKCAiAwrf-bUsFb5aySv2jGDxoD_BwE. Acessado em 2020.

BALDISSERA, A. Pesquisa-ação: uma metodologia do "conhecer" e do "agir" coletivo. In: Sociedade em debate. Pelotas, 2001.

BRASIL. Constituição da República Federativa do Brasil. 1988. http://www.senado.gov.br/sf/legislacao/const/. Acessado em 2015.

Contribuições para Implementação da Lei 10.639/2003. Grupo de Trabalho Interministerial Instituído por Meio da Portaria Interministerial Mec/mj/seppir. No 605 de 20 de Maio de 2008. 58p. 
Diretrizes Curriculares Nacionais para a Educação das Relações Étnicoraciais e para o Ensino de História e Cultura Afro-Brasileira e Africana. Parecer CNE/CP 3/2004, de 10 março de 2004.

Edital Plano Nacional do Livro Didático - PNLD 2014: Anos Finais do Ensino Fundamental. Brasília: MEC, 2013.

2003.

Lei $\mathbf{N}^{\mathbf{0}}$ 10.639, de 9 de janeiro de 2003. D.O.U. de 10/01/2003. Brasília,

Lei $\mathbf{N}^{\circ}$ 11.645, de 10 de março de 2008. D.O.U. 11/03/2008. Brasília, 2008.

Parâmetros Curriculares Nacionais: Pluralidade Cultural, Orientação

Sexual. Secretaria de Educação Fundamental. Brasília: MEC/SEF, 1997. 164p.

CORRÊA, Ricardo Alexandre. O racismo que se perpetua entre os muros das escolas do Brasil. Geledés. Publicado em: 05/05/2018. In: https://www.geledes.org.br/o-racismoque-se-perpetua-entre-os-muros-das-escolas-do-brasil/?gclid=Cjw. Acessado em 2020.

FREIRE, P. Pedagogia do oprimido. Rio de Janeiro: Paz e Terra, 2009.

FREIRE, P. Pedagogia da Autonomia: Saberes necessários à prática educativa. 27. ed. Rio de Janeiro, RJ: Editora Paz e Terra, 1996. 148 p

SOARES, Iasmin. Minha experiência como vítima de racismo na escola. https://medium.com/@iasminsoares/minha-ismo-na-escola-311a3446364f. Acessada em 2020. 